\title{
Römische Gerechtigkeit \\ durch fairen Prozess, Juristen mit Autorität und \\ allgemeingültige Maßstäbe
}

Detlef Liebs

Geriet Rom mit einer anderen Macht in einen ernsten Konflikt, gar einen, der mit Waffengewalt ausgetragen wurde, dann konnten seine Repräsentanten und Organe hart und rücksichtslos reagieren; zu Hause allerdings wurde gründlich und meist auch öffentlich erörtert, inwieweit all das, was geschehen war oder noch geschehen sollte, richtig, vor allem: ob es rechtens sei. ${ }^{1}$ Gleichzeitig wurde Rom in der Mittelmeerwelt dafür geschätzt, dass es Streitigkeiten auf friedliche Weise zu einem Ende zu bringen in der Lage und bereit war. ${ }^{2}$ Soll ein Streit dauerhaft beigelegt werden, dann müssen beide Seiten sich mit der Entscheidung abfinden, was nur gelingt, wenn sie beiden Seiten gerecht geworden ist. Das aber erreicht ein Richter nur, wenn er einen Sinn für elementare Forderungen der Gerechtigkeit hat.

\footnotetext{
* Erschienen in: Ivo De Gennaro (Hg.), Value. Sources and Readings on a Key Concept of the Globalized World (Leiden 2012), 57-82. Hier überarbeitet.

${ }^{1}$ Viele dieser Diskussionen behandelt D. Nörr: Aspekte des römischen Völkerrechts. Die Bronzetafel von Alcántara (München 1989), 87-135; einige wenige auch D. Liebs: Bellum iustum in Theorie und Praxis, in Martin Avenarius u. a. (Hg.): Ars iuris. Festschrift für Okko Behrends zum 70. Geburtstag (Göttingen 2009), 305-318.

${ }^{2}$ Siehe etwa die Entscheidung des Prokonsuls des jenseitigen Spanien wohl 189 v. Chr. in einem Streit zwischen den Einwohnern von Lascuta (bei Cadiz) und der benachbarten Stadt Hasta, erhalten auf der Bronzeinschrift von Alcalà de los Gazules, jetzt im Louvre, s. etwa die Ausgabe von S. Riccobono, in Fontes iuris Romani antejustiniani I (Florenz 1941), 305, Nr. 51; zu Ereignissen des Jahres $161 \mathrm{v}$. Chr. 1. Makkab. 8, 1 u. dazu A. Demandt, Pontius Pilatus (München 2012), 9f.; die Entscheidung des Senats im Grenzstreit zwischen Magnesia am Mäander und Priene 143 v. Chr., hg. etwa von V. Arangio Ruiz, in Fontes III (1943), 501-504, Nr. 162; u. die Entscheidung der vom Senat 117 v. Chr. eingesetzten Schiedsrichter im Grenzstreit zwischen Genua und den benachbarten Viturii Langenses (das heutige Langasco), hg. Arangio Ruiz, a.a.O. 504-509, Nr. 163. Velleius Paterculus: Historia Romana, 2,117,4 - 118,1, erklärt die günstige Resonanz der Rechtsprechung des Quinctilius Varus bei den Germanen freilich für geheuchelt, ähnlich Florus: Epitomae, 2,30,31-33, doch muss man sich fragen, $\mathrm{ob}$ das keine Bewertung ex eventu ist. Anzuführen sind außerdem die mannigfachen Erbeinsetzungen Roms durch hellenistische Herrscher: 162/155 v. Chr. durch Physkon (später Ptomemäus VIII.) bezüglich Kyrenes, 133 v. Chr. durch Attalos III. bezüglich Pergamons und 74 v. Chr. durch Nikomedes IV. bezüglich Bithyniens. - Freilich hat das römische Rechtswesen auch oft versagt; zahlreiche Beispiele solchen Versagens bei K. Wengst: Pax Romana - Anspruch und Wirklichkeit. Erfahrungen und Wahrnehmungen des Friedens bei Jesus und im Urchristentum (München 1986), 53-57.
} 
Erste Voraussetzung dafür, dass Parteien eines Streits annehmen oder wenigstens hinnehmen können, wie ihr Streit durch Dritte beigelegt beziehungsweise entschieden wird, pflegt zu sein, dass schon der Weg, der eingeschlagen wird, um zu der Entscheidung zu gelangen, von beiden Seiten angenommen werden kann. Das aber gelingt nur, wenn der Richter beziehungsweise das Gericht, das am Ende die Entscheidung finden soll, bei beiden Seiten gleichermaßen Autorität hat; und um diese zu gewinnen, muss es beiden Seiten mit dem gleichen Respekt begegnen. In keinem Stadium darf der Eindruck entstehen, als stehe die Entscheidung schon vor Abschluss des Verfahrens mehr oder weniger fest, als sei das Gericht voreingenommen oder auch nur ein Einziger auf der Richterbank befangen.

\section{Audiatur et altera pars}

Zur Unvoreingenommenheit des Richters gehört vor allem, dass er außer dem, der ihn um Hilfe angerufen hat, ebenso die Gegenseite mit der gleichen Gründlichkeit zu Wort kommen lässt. In der Neuzeit fasst man das in der kurzen Sentenz Audiatur et altera pars (Auch die andere Seite muss gehört werden) zusammen; das Grundgesetz der Bundesrepublik Deutschland drückt das mit den Worten aus: „Vor Gericht hat jedermann Anspruch auf rechtliches Gehör.“33 Das gilt, wenn um Mein oder Dein gestritten wird, ebenso wie wenn es darum geht, ob den Verantwortlichen einer Missetat eine Sanktion treffen soll und welche.

\section{a) Seneca über Kaiser Claudius}

In der römischen Literatur findet sich dieser Rechtsgrundsatz erstmals festgehalten, als er von einem hochrangigen Richter wiederholt missachtet wurde, nämlich vom höchsten Richter, dem Kaiser. Es war Claudius, der 41 bis 54 n. Chr. herrschte. Solange seine Herrschaft andauerte, konnte das nur indirekt kritisiert werden. Der stoische Philosoph Seneca schrieb um 50 n. Chr. die Tragödie Medea, ${ }^{4}$ worin der König von Korinth, Kreon, die Heldin des Stücks, eben Medea aus der Stadt gewiesen hat. Sie hatte, [S.59] was allgemein bekannt war, schon zahlreiche schwere Verbrechen für ihren Gatten begangen und jetzt, da dieser sie um der Königstochter willen verstoßen hatte, fürchtete man, dafür werde sie sich furchtbar rächen. In einer Begegnung mit dem König hält sie ihm vor, er habe ohne Prozess ein Urteil über sie

\footnotetext{
${ }^{3}$ Grundgesetz der Bundesrepublik Deutschland Art. 103 Abs. 1.

${ }^{4}$ Zum zeitlichen Ansatz M. Schanz: Geschichte der römischen Literatur II $\left({ }^{4} \mathrm{C}\right.$. Hosius München 1935), 458. J. G. Fitch, Sense-pauses and relative dating in Seneca, Sophocles and Shakespeare, American journal of philology 102 (1981), 289-307, kommt damit gut überein.
} 
gesprochen. ${ }^{5}$ Ihr ist bewusst, dass sie seinerzeit schwere Schuld auf sich geladen hat; und gegenwärtig schmiedet sie tatsächlich Rachepläne. Letztlich um Zeit für deren Ausführung zu gewinnen, aber vorgeblich ein rechtlich einwandfreies Verfahren einfordernd verlangt sie, was der König als Richter - vor Senecas römischem Publikum - nicht ablehnen konnte: dass ihrer Ausweisung aus Korinth ein ordentliches Verfahren mit Urteil vorausgeht; und dazu gehöre vor allem, dass sie gehört werde: „Wer etwas entschieden hat, ohne die andere Seite gehört zu haben, hat, auch wenn er gerecht entschieden hat (gemeint: in der Sache gerecht), in keiner Weise gerecht gehandelt. “6

Etwa fünf Jahre später, nachdem Claudius gestorben ist, verfasste Seneca eine Satire über den verstorbenen Kaiser. In der Unterwelt besingt ein großer Chor seine Taten. Als Richter und überhaupt bei Ausübung seiner Herrschaft ${ }^{7}$ hatte er seiner Willkür oft und oft freien Lauf gelassen, insbesondere die hier interessierende Maxime immer wieder missachtet, woraus aber nicht zu shließen ist, dass sie damals von Rechts wegen nicht gegolten hätte. Worte des Chores nehmen auf sie als geltendes Recht Bezug: ${ }^{8}$

Oh, beklaget den Mann, der wie keiner so rasch bei Prozessen entschied, wenn nur eine Partei er zu hören geneigt oder keine oft auch!

Und im weiteren Verlauf begegnen ihm unter den von ihm ermordeten 35 Senatoren, 221 Rittern und unzähligen einfachen Bürgern vor allen anderen die vielen, die ihm besonders nahe gestanden hatten. Wegen dieser seiner Morde wird jetzt ihm, Claudius der Prozess gemacht, und [60] zwar an sich wie in einem römischen Strafprozess. Aber nachdem die Anklage unter großem Beifall erhoben worden ist und der Verteidiger des verstorbenen Gewaltherrschers - es war schwer, einen zu finden - das Wort ergreifen will, verbietet ihm das der Vorsitzende, „die Gerechtigkeit in Person (homo iustissimus), und fällt, nachdem er nur die Gegenseite angehört hat, das Schuldurteil über ihn (et illum altera tantum parte audita condemnat).“ Er begründet das mit einem Hesiod-Zitat auf Griechisch: „Was er getan, das erleide er; gerechtes Recht widerfahre ihm.“ Seneca fährt fort: „Da wurde es totenstill. Ganz verblüfft sind alle, wie vom Donner gerührt angesichts dieses unerhörten Vorgangs; so etwas habe es

\footnotetext{
${ }^{5}$ Das ist ihren Worten bei Seneca: Medea, 192 u. 194, zu entnehmen.

${ }^{6}$ Seneca: Medea, 199f.: Qui statuit aliquid parte inaudita altera, aequum licet statuerit, haud aequus fuit; Übersetzung: Th. Thomann. Dazu A. Wacke: Audiatur et altera pars. Zum rechtlichen Gehör im römischen Zivil- und Strafprozeß, in: ders.: Unius poena - metus multorum. Abhandlungen zum römischen Strafrecht (Neapel 2008), 149-179 (zuerst 1993), hier 155. In Senecas hauptsächlicher Vorlage, der Medeia von Euripides, gebraucht sie dieses Argument nicht.

${ }^{7}$ Siehe dazu auch Sueton, Claudius, 29,1.

${ }^{8}$ Seneca, Apocolocyntosis, 12,3: Deflete virum, quo non alius / potuit citius discere causas, / una tantum parte audita, / saepe et neutra; s. a. 14,2: altera tantum parte audita condemnat; Übersetzung: A. Bauer.
} 
noch nie gegeben, sagen sie. Claudius fand es eher ungerecht als neu. ${ }^{69}$ Die Gegenseite nicht zu Wort kommen zu lassen, ist klares Unrecht; nur diesem Mann gegenüber, der als Richter selbst so gehandelt hatte, ist es richtig.

\section{b) Sueton über Claudius}

Etwa 70 Jahre später beurteilt Sueton, Literat im Dienst der „guten“ Kaiser Trajan und Hadrian, Claudius ebenso. Seinen Beispielen für Zivilprozesse stellt er sein Urteil voran: „Bei der Untersuchung und Entscheidung war er von erstaunlicher Sprunghaftigkeit, manchmal umsichtig und schlau, bisweilen unbedacht und voreilig, nicht selten abgeschmackt und einem Verrückten ähnlich.“" ${ }^{10}$ Er belegt das unter anderem damit, dass der Kaiser, wenn eine Partei nicht erschienen war, sehr rasch der anwesenden recht gab, ohne - wie es rechtens gewesen wäre - zu unterscheiden, ob die andere Seite schuldhaft oder aus einem triftigen Grund säumig war. ${ }^{11}$ Säumig kann nur genannt werden, wer geladen ist; die Partei, zu deren Lasten Claudius das Urteil sprach, war gewiss geladen worden, weshalb sie ihre Sache an sich hätte vertreten können. Nach Suetons Rechtsempfinden, und darin hätten ihm die Rechtskenner damals zugestimmt, genügte die bloße Formalität einer Ladung zum Gerichtstermin jedoch nicht; vielmehr musste, damit jemand in Abwesenheit verurteilt beziehungsweise seine Klage abgewiesen werden, ein sogenanntes Versäumnisurteil ergehen konnte, hinzukommen, dass [61] der Geladene den Termin auch hätte wahrnehmen können, ihm schuldhaft ferngeblieben ist. Die Ladung mochte ihn gar nicht erreicht haben; möglicherweise war er unverschuldet verhindert, durch Krankheit ${ }^{12}$ oder unaufschiebbare andere Aufgaben, so wenn ein öffentliches Interesse daran bestand, dass diese vorrangig erledigt würden. Rechtliches Gehör war erst gewährt, wenn es dem Betreffenden auch möglich war, seine Sache zu vertreten. Zu prüfen, ob auch das gegeben war, gab Claudius sich keine Mühe, sondern begnügte sich zu oft damit, dass eine formelle Ladung hinausgegangen war.

Verhängnisvoller wirkte sich aus, dass Claudius das Recht auf Gehör nicht einmal dann achtete, wenn es um Verbannung oder Hinrichtung eines - vorerst nur angeblichen - Delinquenten ging. Dazu benennt Sueton je zwei Fälle. Verbannung verfügte er gegen einen un-

\footnotetext{
${ }^{9}$ Seneca, Apocolocyntosis, 13,4-14,3.

${ }^{10}$ Sueton, Claudius, 15,1, S. 1: In cognoscendo autem ac decernendo mira varietate animi fuit, modo circumspectus et sagax, interdum inconsultus ac praeceps, nonnumquam frivolus amentique similis. Übersetzung: A. Lambert.

${ }^{11}$ Sueton, Claudius, 15,2, S. 2: Absentibus secundum praesentes facillime dabat, nullo dilectu culpane quis an aliqua necessitate cessasset.

${ }^{12}$ In der römischen Rechtsliteratur, deren Überlieferung erst etwa hundert Jahre später reicher einsetzte, sagt Julian um 150 n. Chr., Digesta V (in Dig., 42,1,60), auch gegen einen zwar Geladenen, aber wegen einer ernsten Erkrankung Abwesenden dürfe kein Urteil ergehen, und wenn es trotzdem erging, sei es unbeachtlich.
} 
schuldigen Schreiber eines Quästors, ohne ihn auch nur vor Gericht zu laden. Als Claudius noch Privatmann gewesen war, damals gering geachtet, war dieser Schreiber in einem Rechtsstreit, an dem Claudius beteiligt war, ihm gegenüber heftig geworden. Einen Senator im Rang eines ehemaligen Prätors verbannte er ohne Prozess, weil dieser in einem früheren Amt, als Ädil, eine Art Polizeipräsident, einen kaiserlichen Sklaven in höherer Stellung hatte auspeitschen lassen, der vereitelt hatte, dass sein Verbot bestimmter Gewerbe auf kaiserlichen Gütern durchgesetzt wird. ${ }^{13}$ Hinrichten ohne Verfahren ließ Claudius den Vater des Verlobten seiner jüngeren Tochter, einen Senator; er war der Frau des Claudius, Messalina, und seinem einflussreichen Freigelassenen und Beamten, Narziss, unliebsam; ${ }^{14}$ ferner eine Nichte und eine Großnichte, beide namens Julia, und den Ehemann seiner älteren Tochter. ${ }^{15}$ Den Verlobten seiner jüngeren Tochter, damals Prätor, zwang er am 29. Dezember, also drei Tage bevor dessen Amt ohnehin endete, zurückzutreten, und am Neujahrstag, [62] Selbstmord zu begehen. ${ }^{16}$ Viele Ungenannte kommen hinzu; insgesamt ist mit Hunderten zu rechnen. ${ }^{17}$

\section{c) Die Apostelgeschichte über einen Mann Senecas}

Um rechtliches Gehör in einem Strafprozess ging es auch beim Apostel Paulus. Die jüdische Obrigkeit, Hohepriester und Älteste, wollten ihn 60 n. Chr. vor dem neuen Statthalter Roms in Judäa, Porcius Festus, der sich gerade in Jerusalem aufhielt, eines Verbrechens anklagen. Paulus war in Jerusalem festgenommen und vom Vorgänger des Festus, Marcus Antonius Felix, in die Provinzhauptstadt Cäsarea verbracht worden. Bald nach seinem kurzen Besuch in der Heiligen Stadt weilte Festus wieder in Cäsarea, als Agrippa II., römischer Klientelkönig um Golan östlich des Sees Genezareth, mit seiner Schwester Berenike ihn dort besuchte, um den neuen Repräsentanten Roms in Judäa zu begrüßen. Dabei berichtete ihnen Festus, die Juden in Jerusalem hätten ihm angesonnen, Paulus in Abwesenheit zum Tode zu verurteilen. Er habe ihnen erwidert, bei den Römern sei es nicht üblich, irgendjemanden hinzurichten, bevor er seinen Anklägern gegenüberstand und Gelegenheit bekommen hat, sich gegen Anschuldigun-

\footnotetext{
${ }^{13}$ Sueton, Claudius, 38,2: inauditos et innoxios relegavit.

${ }^{14}$ Sueton, Claudius, 37,2: arcessi statim ac mori iussus est; u. 29,1, S. 2 Hs. 2 : crimine incerto nec defensione ulla data occidit.

${ }^{15}$ Sueton, Claudius, 29,1, S. 2 Hs. 2 (wie soeben).

${ }^{16}$ Sueton, Claudius, 29,1f.; s. a. 27,2. Allgemein zu der Möglichkeit, einen Missliebigen loszuwerden, indem der Machthaber ihm den Rat zukommen lässt, Selbstmord zu begehen, im 1. Jahrhundert n. Chr. vielfach praktiziert, D. Liebs: Nerva filius -Selbstmord auf Wunsch des Kaisers?, in Festschrift für Rolf Knütel zum 70. Geburtstag (Heidelberg 2009), 651-665.

${ }_{17}$ Siehe Sueton, Claudius, 37,1; u. vor allem 29,2. Seneca, Apocolocyntosis, 13,4-14,1, nennt viele Namen; insgesamt zählt er (14,1) 35 Senatoren, 221 Ritter und sonstige Bürger so viele wie Sand am Meer. Auch Kaiser Galba (68/69 n. Chr.) verurteilte selbst Senatoren und Ritter auf den geringsten Verdacht hin und ohne sie angehört zu haben (suspicione minima inauditos), Sueton, Galba, 14,3.
} 
gen zu verteidigen. Sobald er nach Cäsarea zurückgekehrt sei, habe er deshalb den Mann vor sein Tribunal bringen lassen und seinen Anklägern gegenübergestellt. Dabei sei von den Anschuldigungen nichts Belastendes übrig geblieben. ${ }^{18}$

Von diesen Worten des Statthalters ist in unserem Zusammenhang bemerkenswert, dass nach dem vom selben Lukas zuvor Berichteten ${ }^{19}$ die Juden von dem Römer keineswegs schon Preisgabe, also Hinrichtung des abwesenden, im $100 \mathrm{~km}$ entfernten Cäsarea einsitzenden Apostels verlangt hatten. Sie hatten Festus lediglich ihre Klagen über Paulus vorgetragen und ihn um die Gunst gebeten, er möge den Mann nach Jerusalem kommen lassen. Und die Ant[63]wort des Statthalters Roms bestand nach diesem Bericht darin, dass er darauf verwies, der Beschuldigte sei nun einmal in Cäsarea, wohin er in Kürze zurückkehren und wo er öffentlich Gericht halten werde; dann hätten ihre Bevollmächtigten Gelegenheit, den Mann anzuklagen. Die Juden hatten also wenigstens vorgegeben, Paulus rechtliches Gehör zu gewähren, aber mit dem Hintergedanken, ihn unterwegs durch eine bereitstehende Jungmannschaft überfallen und ermorden zu lassen. Festus mag durchschaut haben, dass die jüdische Obrigkeit Paulus nur kommen lassen wollte, um ihn umzubringen. Was er ihnen damals geantwortet hatte: kurz und bündig auf den Haftort des Paulus verwiesen und seine Absicht, dort, wo auch sein Hauptsitz war, Gericht zu halten, diese schroffe Antwort und seinen Verdacht gegenüber dem Ururenkel von Herodes dem Großen zu wiederholen, einem Verbündeten Roms, der auch über jüdisches Land herrschte, mag ihm unpassend erschienen sein. Stattdessen nahm er eine Gelegenheit wahr, die römische Rechtskultur herauszustellen, nämlich die eigene Art, Gerechtigkeit herzustellen, indem er dem Klienten Roms einen zentralen Verfahrensgrundsatz an einem Beispiel vorführte. Dabei stellte er es so hin, als hätten die jüdischen Hohenpriester und Ältesten, die das jüdische Recht gekannt haben werden, ihn dazu bringen wollen, über diesen Grundsatz hinwegzugehen, der in der Sache auch bei ihnen galt. ${ }^{20}$ Vorgegeben hatten sie wie gesagt etwas anderes; in Wahrheit aber wollten sie durchaus Paulus ohne Prozess töten, getrieben von blinder Wut gegen die Christen. Festus, noch ein Mann Senecas - in Neros ersten Jahren leitete Seneca die Regierung für ihn ${ }^{21}$-, war unbestechlich, anders als Felix, sein Vorgänger in Judäa, ein Mann des Claudius oder richtiger seiner Freigelasse-

\footnotetext{
${ }^{18}$ Acta apostolorum, 25,13-20. Zum Prozess des Paulus zuletzt etwa Monika Schuol: Augustu und die Juden (Frankfurt am Main 2007), 211-224 u. 338.

${ }^{19}$ Acta apostolorum, 25,1-5.

${ }^{20}$ Vgl. Jesus Sirach 11,7f.; s. auch Sprüche Salomos 18,13. Klarer bezeugt ist er für das attische Recht, wo der von allen Geschworenenrichtern alljährlich zu leistende Eid u. a. lautete: „Ich will den Kläger und den Beklagten beide auf gleiche Weise anhören und mein Urteil nur auf den Gegenstand der Klage selbst richten.“, Justus Hermann Lipsius: Das Attische Recht und Rechtsverfahren I (Leipzig 1905), 152 u. Fn. 56.

${ }^{21}$ Dazu etwa M. Fuhrmann: Seneca und Kaiser Nero. Eine Biographie (Berlin 1997), 155-275.
} 
nen. ${ }^{22}$ Festus nahm die römischen Werte ernst ${ }^{23}$ und warb mit ihnen gegenüber dem Fremdstämmigen, bei einem Mann Senecas nicht überraschend.

\section{[64] d) Ulpian über Kaiser Trajan}

Der Jurist Ulpian berichtet, Trajan, der 98 bis $117 \mathrm{n}$. Chr. herrschte und als besonders fair und zugleich kraftvoll in die Geschichtsbücher eingegangen ist, habe - offenbar einem Provinzstatthalter - den nachdrücklichen Bescheid gegeben, ein Abwesender dürfe nicht wegen eines Verbrechens verurteilt werden. ${ }^{24}$ Im 2. Jahrhundert wird unsere Überlieferung aus der Rechtsliteratur merklich besser und dementsprechend reißen seitdem auch die Bezeugungen dieses Grundsatzes nicht mehr ab Der Jurist Marcian bezeichnet ihn als eine Forderung der Gerechtigkeit. ${ }^{25}$ Die Kaiser Philipp der Araber, der 244 bis 249 n. Chr. herrschte, und Diokletian, 284 bis 305, erklärten ein Gerichtsurteil für unbeachtlich, das ergangen ist, ohne dass beide Seiten ordnungsgemäß gehört wurden. ${ }^{26}$ Jetzt geht es meist nur noch darum, Reichweite und Grenzen des Grundsatzes genauer zu bestimmen. Seit alters galt er dann nicht, wenn der Täter auf frischer Tat ertappt wurde, wodurch die Tat für die Rechtsgemeinschaft offenkundig war. ${ }^{27}$ Und wenn der Betreffende zwar ordnungsgemäß geladen worden war, im Termin jedoch ohne triftigen Grund ausblieb, konnte gegen ihn wie gesagt ein Versäumnisurteil ergehen. ${ }^{28}$ Dadurch konnte aber höchstens leichte Verbannung verhängt werden; ${ }^{29}$ weder Todes-

\footnotetext{
${ }^{22}$ Tacitus, Annalen, 12,54; u. Sueton, Claudius, 28,1; Marcus Antonius Felix war wie sein nicht weniger bestechlicher Bruder Marcus Antonius Pallas freigelassener Sklave der Mutter des Claudius. Die Bestechlichkeit von Felix bezeugen Tacitus a.a.O. und Acta apostolorum, 24,26.

${ }^{23}$ Gewiss haben sich nicht alle römischen Richter stets daran gehalten; vielmehr konnte die Geduld mit einem Angeklagten oder einem Schuldner leicht umschlagen und auch ein römischer Richter sein Opfer, wenn er es aufgegeben hatte, demütigen, s. dazu etwa M. Peachin, Attacken und Erniedrigungen als tägliche Elemente der kaiserzeitlichen Regierungspraxis, in R. Haensch u. J. Heinrichs (Hgg.), Herrschen und Verwalten. Der Alltag der römischen Administration in der römischen Kaiserzeit (Köln 2007), 117-125.

${ }^{24}$ Ulpian: De officio proconsulis VII (in Dig., 48,19,5pr.): Absentem in criminibus damnari non debere divus Traianus Iulio Frontoni rescripsit.

${ }^{25}$ Marcian: De iudiciis publicis II (in Dig., 48,17,1pr.): neque enim inaudita causa quemquam damnari aequitatis ratio patitur. Entzog sich allerdings ein Beschuldigter einem Prozess, dann konnte, wenn bestimmte Formalien eingehalten wurden, auch gegen einen Abwesenden verhandelt werden, Th. Mommsen: Römisches Strafrecht (Leipzig 1899), 149 u. 332-336.

${ }^{26}$ Philipp (in Cod. Just., 7,43,5): quod ita gestum est, ad effectum iuris spectare minime oportet; ein Provinzstatthalter hatte einen Verhandlungstermin an einem bestimmten Ort terminiert, war dann aber von der anderen Seite andernorts beschlichen worden und entschied dort in Abwesenheit des Gegners. Ferner Diokletian 1. Sept. 287 (in Lex Rom. Visig. Cod. Greg., 13): Sententiam adversus absentes et indefensos ac maxime minores latam nullas vires obtinere notissimi iuris est; u. ders. 30. März 290 (in Cod. Just., 7,43,7): ... certum est.

${ }^{27}$ Siehe etwa Labeo bei Pomponius: Ad Sabinum XXII (in Dig., 12,4,15): quasi in facinore deprehensum; Sueton: Claudius, 37,1 a. E.: pro deprehenso; u. dazu Wacke (oben Fn. 6), 167f.

${ }^{28}$ Das bezeugen Julian: Digesta V (Dig. 42,1,60); Ulpian, De officio proconsulis VII (Dig. 48,19,5pr. S. 3-5); u. Diokletian (in Cod. Just., 7,43,7).
} 
strafen noch Deportation noch Zwangsarbeit. Diese Strafen konnten ohnehin erst vollstreckt werden, wenn man des Betreffenden habhaft geworden war. Gegen [65] Verdächtige eines schweren Verbrechens, die flüchtig waren, wurden Suchbefehle ausgeschrieben. ${ }^{30}$

\section{2. Öffentlichkeit}

$\mathrm{Zu}$ einem fairen Gerichtsverfahren gehörte nach römischer Auffassung zudem, dass ein Prozess öffentlich geführt wurde, ${ }^{31}$ was Beeinflussung durch Bestechung, sonstwie voreingenommene Prozessführung und auch eine lustlos formale Prozessführung sehr erschwert. So belehrte Kaiser Konstantin, der von 306 bis 337 n. Chr. herrschte, im Jahr 315 den Prokonsul der Provinz Africa (das mittlere Nordafrika) mit den Worten: „Alle Zivilsachen, vor allem die, welche in der Öffentlichkeit Aufsehen erregen, und ebenso die Strafprozesse musst du öffentlich hören ... “;32 und knapp 20 Jahre später bestimmte er in einem Edikt: ${ }^{33}$

Die Gouverneure sollen öffentlich Gericht halten, ihr Tribunal während der ganzen Verhandlung gut besucht sein und sie sollen sich auch bei Zivilprozessen nicht in geschlossenen Räumen verbergen; es darf nicht sein, dass jemand, der einen Prozess führen will, nur wenn er bezahlt die Möglichkeit hat, eine Klage anzubringen. Erst nachdem sie alle Sachen, die vor sie gebracht worden sind, angehört haben, der mehrmalige und vernehmliche Aufruf des Herolds niemanden mehr aufgespürt hat, der ein Anliegen vorbringen wollte, und sie alle Strafund Zivilverfahren erledigt haben, mögen sie sich zurückziehen.

Und der im Westen 364 bis 375 herrschende Valentinian I. ermahnte 364 n. Chr. den Gouverneur von Lukanien und Kalabrien: ${ }^{34}$

[66] Ein Richter soll nicht zweifeln, dass ihm als wichtigste Aufgabe auferlegt ist, Rechtsstreitigkeiten anzuhören und zu entscheiden; und zwar soll er nicht in der Abgeschiedenheit eines Hauses über den Status eines Menschen oder sein Vermögen Urteile fällen, sondern

\footnotetext{
${ }^{29}$ Ulpian: De officio proconsulis VII (in Dig., 48,19,5pr.): was über leichte Verbannung (relegatio) hinausgeht; u. Marcian: De iudiciis publicis II (in Dig., 48,17,1 § 1).

${ }^{30}$ Marcian ebenda $\S \S 1-4$.

${ }^{31}$ Mommsen, Strafrecht, 359; s. a. S. 148f.; u. L. Bablitz, Actors and Audience in the Roman Courtroom (London 2007). Ausdrücklich formuliert findet sich dieses Erfordernis allerdings erst in der Spätantike, s. die Nachweise bei Mommsen, Strafrecht, 359 Fn. 1.

${ }^{32}$ In Cod. Theod., 1,12,1: Omnes civiles causas et praecipue eas, quae fama celebriores sunt, negotia etiam criminalia publice audire debebis ...; das Gesetz erging möglicherweise schon 313.

${ }^{33}$ In Cod. Theod., 1,16,6, S. 1: Praesides publicas notiones exerceant frequentatis per examina tribunalibus, nec civiles controversias audituri secretariis sese abscondant, ut iurgaturus conveniendi eos nisi pretio facultatem impetrare non possit; et cum negotiis omnibus, quae ad se delata fuerint, exhibuerint audientiam et frequens praeconis, ut adsolet fieri, inclamatio nullum, qui postulare voluerit, deprehenderit, expletis omnibus actibus publicis privatisque sese recipiant.

${ }^{34}$ In Cod. Theod., 1,16,9, S. 1: Iudex sibi hanc praecipuam curam in audiendis ac discingendis litibus inpositam esse non ambigat, ita ut non in secessu domus de statu hominum vel patrimoniorum sententiam ferat, sed apertis secretarii foribus intro vocatis omnibus aut pro tribunali locatus et civiles et criminales controversias audiat, ne congruae ultionis animadversione cohibeatur.
} 
nachdem die Türen des Gerichtssaals geöffnet und alle hereingerufen worden sind, oder aber im Freien vor dem Gerichtsgebäude sowohl die Zivil- als auch die Strafprozesse anhören, damit er in der Lage ist, in jedem Fall die angemessene Sanktion zu verhängen.

Auch vom Grundsatz der Öffentlichkeit wurden Ausnahmen gemacht, vor allem wenn das Staatsinteresse es forderte. Ob das der Fall war, beurteilte der Richter. So verhandelte Augustus den Ehebruchsprozess gegen Ovid nichtöffentlich. ${ }^{35}$ Unter Nero verlegte der Prätorianerpräfekt Tigellinus den vor seinem Richterstuhl geführten Majestätsprozess gegen Apollonius von Tyana in ein verschlossenes Gemach, zu dem niemand Zutritt hatte. ${ }^{36}$ Und ebenso hielten es Provinzstatthalter in Prozessen gegen Christen, wenn sie verhindern wollten, dass diese die öffentlichen Verfahren zur Werbung für ihren Glauben umwidmeten. ${ }^{37}$ Prozesse vor dem Senat waren lediglich senatsöffentlich. ${ }^{38}$

\section{Anonyme Anzeigen}

Anonymen Anzeigen durften die römischen Behörden nicht nachgehen. Im Altertum und auch im Mittelalter gab es keine Staatsanwaltschaft. Straftaten kamen auf Betreiben von Bürgern vor Gericht, die bereit waren, eine Anklage zu vertreten. Dabei riskierten sie, bei Misslingen ihrerseits wegen leichtfertiger oder schikanöser Anklage vor Gericht gestellt zu werden. Wer unter diesen Bedingungen anonym anzeigt, scheut sich, diese Verantwortung zu übernehmen. Weil außerdem damals anonyme Anzeigen nicht wie heute von einer Behörde wie unserer Staatsanwaltschaft, die zu Objektivität verpflichtet ist, überprüft worden wären, hätte der Magistrat, [67| bei dem die Anzeige einging, einen erprobten Ankläger mit der Sache betraut, der ohne Führung durch einen Staatsanwalt sie eher selbstherrlich weiterverfolgt hätte. Private Strafverfolger neigen dazu, auch Beschuldigungen aus dem Hinterhalt Glauben zu schenken und einseitig zu ermitteln, statt sie skeptisch zu prüfen; im Schutze eines Auftraggebers brauchten sie oft kaum zu fürchten, wegen der Art ihres Vorgehens zur Verantwortung gezogen zu werden. Kaiser Trajan betonte deshalb um 110 n. Chr., dass anonyme Anzeigen niemals zu berücksichtigen sind. Anlass war eine Anfrage seines Statthalters in der Provinz Pontus und Bithynien (nördliches Kleinasien), des bekannten Literaten Plinius des Jün-

\footnotetext{
${ }^{35}$ D. Liebs: Vor den Richtern Roms. Berühmte Prozesse der Antike (München 2007), 82.

${ }^{36}$ Philostratus: Vita Apollonii, 4, 44, 2.

${ }^{37}$ So der Prokonsul von Africa $180 \mathrm{n}$. Chr. in Karthago gegen zwölf Christen aus dem unweiten Scilli, D. Liebs, Das Recht der Römer und die Christen (Tübingen 2015) 60-63; ebenso im späten 3. Jahrhundert im Prozess gegen Cyprian, Acta proconsularia Cypriani, 1; in der Passio Montani et Lucii, 6; in der Passio Crispinae (Karthago 304 n. Chr.), 1; oder in den Acta Eupli, 1; s. auch Laktanz: De mortibus persecutorum, 15, 5. Dazu J.-J. Aubert: The setting and staging of Christian trials, in: F. de Angelis (Hg.), Spaces of justice in the Roman world (Leiden 2010), 277-309, hier 284-296.

${ }^{38}$ Mommsen, Strafrecht, 254.
} 
geren. Er hatte Zweifel bekommen, ob Christentum wirklich ein todeswürdiges Verbrechen sei, war allerdings auch anonymen Anzeigen nachgegangen. ${ }^{39}$ Deshalb schloss der Kaiser, nachdem er die Fragen seines Mannes in Kleinasien zur Behandlung der Christen kurz beantwortet hatte, ${ }^{40}$ seinen Brief mit einer allgemeinen Mahnung, nicht nur für Christenprozesse: ${ }^{41}$

Anonym zur Kenntnis gebrachte Anzeigeschreiben dürfen jedoch bei keinem Verbrechen beachtet werden; denn das gäbe ein sehr schlechtes Beispiel und passt nicht in unsere Zeit.

Damit setzte sich Trajan, dem es gelungen war, in der öffentlichen Meinung sehr gut beurteilt zu werden, auch von Praktiken bei manchem Vorgänger ab, die im allgemeinen Rechtsbewusstsein als gemeingefährlich und rechtswidrig galten. Kaiser Konstantin sollte das im Jahr 328 noch einmal einem Provinzgouverneur mit den Worten einschärfen: ${ }^{42}$

Eine Schrift mit Beschuldigungen, in welcher der Name des Anklagenden fehlt, darf in keiner Weise ernst genommen, sondern muss vollständig vernichtet werden. Denn wer sich zutraut, eine Anklage zu betreiben, muss das Leben eines andern in freiem Bemühen vor dem Richterstuhl aufs Spiel setzen, nicht aufgrund einer flüchtigen und Versteck spielenden Aufzeichnung.

[68] II. JURISTEN

\section{Die Assessur}

Um 390 n. Chr. berichtet der römische Historiker Ammian in einem Exkurs über Persien auch über Sitten und Bräuche der Perser. ${ }^{43}$ Er schreibt: ${ }^{44}$

Zum Richten aber werden erfahrene und angesehene Männer bestimmt, die unbestechlich sind und nur selten fremden Rat nötig haben, weshalb sie (die Perser) unsere Art und Weise, sehr Fähige und in Recht und Gesetz bestens Bewanderte oft hinter Ungebildete zu setzen, lächerlich finden.

\footnotetext{
${ }^{39}$ Plinius: Epistulae, 10,96,5f.

${ }^{40}$ Der häufig erhobene Vorwurf, Trajan habe sich zur Hauptfrage, ob überhaupt Todesstrafe die angemessene Sanktion für Christentum sei, nicht geäußert, ist unberechtigt, s. Liebs: Vor den Richtern Roms (oben Fn. 35), S. 122 f.

${ }^{41}$ Plinius: Epistulae, 10,97(98),2, S. 2: Sine auctore vero propositi libelli nullo crimine locum habere debent; nam et pessimi exempli nec nostri saeculi est.

${ }^{42}$ In Cod. Theod., 9,34,4: Famosa scribtio libellorum, quae nomine accusatoris caret, minime examinanda est, sed penitus abolenda. Nam qui accusationis promotione confidat, libera potius intentione quam captiosa atque occulta conscribtione alterius debet vitam in iudicium devocare.

${ }_{43}^{43}$ Ammian: Res gestae, 23,6,75-84, der Schluss des Exkurses.

${ }^{44}$ Ammian: Res gestae, 23,6,82: Ad iudicandum autem usu rerum spectati destinantur et integri, parum alienis consiliis indigentes, unde nostram consuetudinem rident, quae interdum facundos iurisque publici peritissimos post indoctorum conlocat terga.
} 
Ammian meint damit den Eindruck, den die spezifisch römische Einrichtung der Assessur bei Fremden hinterließ. Die Richter, meist die Gouverneure, aber ebenso die anderen Magistrate waren allenfalls ausnahmsweise juristisch bewandert; um öffentlich auftreten zu können, wurde man zum Herrschen und Befehlen erzogen und rhetorisch geschult. Die Magistrate verdankten ihre Stellung einer politischen oder auch militärischen Karriere; und Militärs waren tatsächlich oft roh und ungebildet. ${ }^{45}$ Um auch seine richterlichen Aufgaben - das waren nicht seine einzigen - erfüllen zu können, hatte jeder Magistrat einen Beraterstab, dem möglichst ein ausgebildeter Jurist angehörte; in der konsolidierten Kaiserzeit gab es dafür die Planstelle des fest besoldeten Beisitzers (assessor). Er stand dem Magistrat vor allem als Fachmann für Rechtsfragen zur Seite und dieser folgte gewöhnlich seinem Rechtsrat ohne Weiteres, ${ }^{46}$ vermied es, davon abzuweichen; das hätte ihn in der öffentlichen Meinung herabsetzen können. So berichtet Augustin von seinem wenig jüngeren Schüler Alypius, der nach abgeschlossener rhetorischer Ausbildung bei ihm [69] nach Rom ging und dort Jura studierte, dass er 384 n. Chr. Assessor beim Finanzchef Süditaliens (comes largitionum Italicianarum) war, der in Rom residierte. Als dieser einem rechtswidrigen Ansinnen eines einflussreichen und mit Geld nicht sparenden Senators gern stattgegeben hätte, lehnte Alypius das ab und setzte sich durch; der Senator wurde abgewiesen. ${ }^{47}$ Die Juristen wurden allgemein respektiert, wenn auch nicht alle wagten, sich solchem Einfluss zu widersetzen.

\section{Jurisprudenz}

Die in einem fünfjährigen Fachstudium besonders ausgebildeten Fachleute des Rechts: iuris periti, iuris prudentes, iuris consulti oder iuris studiosi, waren eine Besonderheit des öffentlichen Lebens im römischen Reich. Es gab sie seit ältester Zeit, als Rom noch ein kleiner Stadt-

\footnotetext{
${ }^{45}$ Siehe etwa Laktanz: De mortibus persecutorum, 22,5, wonach Galerius rohe und ungebildete Militärs (militares humanitatis litterarum rudes) zu Provinzgouverneuren machte. Da die Provinzen kurz vorher verkleinert worden waren, so dass binnen kurzem etwa doppelt so viele Gouverneure zu bestellen waren, wird das kein Einzelfall gewesen sein.

${ }^{46}$ Siehe etwa Seneca: De tranquillitate animi, 3,4 (angeblich argumentiert Athenodorus von Tarsus in den 40er oder 30er Jahren v. Chr.); Paulus: Ad edictum praetoris III (in Dig., 2,2,2); ders.: De officio adsessorum (in Dig., 1,22,1); Konstantin 320 n. Chr. (in Cod. Just., 1,51,2); u. dazu O. Behrend, Der assessor zur Zeit der klassischen Rechtswissenschaft, Zeitschrift der Savigny-Stiftung für Rechtsgeschichte Romanistische Abteilung 86 (1969), 192-226, hier 194-203 u. 225.

${ }^{47}$ Augustin: Confessiones, 6,10; u. dazu D. Liebs, Nichtliterarische römische Juristen der Kaiserzeit, in: K. Luig u. D. Liebs (Hgg.): Das Profil des Juristen in der europäischen Tradition. Symposion aus Anlaß des 70. Geburtstages von Franz Wieacker (Ebelsbach 1980), 123-198, hier 189-191.
} 
staat war. Der Abriss einer Geschichte der römischen Rechtswissenschaft von Pomponius, verfasst um $130 \mathrm{n}$. Chr., beginnt wie folgt: ${ }^{48}$

Viele und bedeutende Männer haben die Wissenschaft vom Recht der Bürger gelehrt; und die unter ihnen, welche beim römischen Volk in besonders hohem Ansehen standen, sind im Folgenden festzuhalten, damit man sieht, von wem dieses Recht seinen Ursprung, wer es überliefert hat und was für Männer das waren. Und von allen, die Kennerschaft in diesem Fach erlangt hatten, habe, wie es heißt, vor Tiberius Coruncanius niemand es öffentlich gelehrt. Die anderen bis auf ihn waren nämlich sehr darauf bedacht, das Recht der Bürger im Verborgenen zu halten, und nahmen sich lieber Zeit für die, welche sie um Rat fragten, als sich Lernbegierigen zur Verfügung zu stellen.

Dem akademischen Juristen Pomponius ist der Rechtsunterricht besonders wichtig. Coruncanius hatte im frühen 3. Jahrhundert v. Chr. in seiner latinischen Vaterstadt zur Oberschicht gehört, siedelte nach [70] Rom über, wo er nur Plebejer war, gelangte dort in das auf Privatrechtskunde spezialisierte Kollegium der pontifices und wurde auch pontifex maximus; er war der erste plebejische. Im Gegensatz zu ihm sahen alle anderen pontifices ihre Hauptaufgabe darin, für diejenigen Zeit zu haben, die Rechtsrat in einem konkreten Fall benötigten; genaue Rechtskunde wurde nur im zunächst sechs- und seit 300 v. Chr. (lex Ogulnia, ein Plebiszit) neunköpfigen Pontifikalkollegium weitergegeben. Diese Beratung heischten nicht nur Privatleute, sondern ebenso Magistrate. Sie blieb die Hauptaufgabe der römischen Juristen bis in die Spätantike.

Seit dem 3. Jahrhundert v. Chr. war Rechtswissenschaft also auch Laien zugänglich, wiewohl die führenden Juristen lange Zeit noch immer pontifices waren. Vor allem blieb ein gründliches, langjähriges Studium immer erforderlich, wollte man in der Gesellschaft als einer der verhältnismäßig wenigen iuris consulti, periti usw. mit Autorität anerkannt sein; auch weniger guten Juristen kam diese Autorität zu. ${ }^{49}$ Das römische Volk verehrte sie alle, die sich uneigennützig allen Rechtsuchenden kostenlos zur Verfügung stellten. Pomponius berichtet weiter: ${ }^{50}$

\footnotetext{
${ }^{48}$ Pomponius: Enchiridii liber singularis (in Dig., 1,2,2 § 35): Iuris civilis scientiam plurimi et maximi viri professi sunt; sed qui eorum maximae dignationis apud populum Romanum fuerunt, eorum in praesentia mentio habenda est, ut appareat, a quibus et qualibus haec iura orta et tradita sunt. Et quidem ex omnibus, qui scientiam nancti sunt, ante Tiberium Coruncanium publice professum neminem traditur; ceteri autem ad hunc vel in latenti ius civile retinere cogitabant solumque consultatoribus vacare potius quam discere volentibus se praestabant.

${ }^{49}$ Augustin: De duabus animabus contra Manichaeos, $\S 5$; ders.: Enarratio in Psalmum 145, $\S 4$; u. dazu D. Liebs: Die Jurisprudenz im spätantiken Italien (Berlin 1987), 102f.

${ }_{50}$ Pomponius ebenda (in Dig., 1,2,2 § 37): Fuit post eos maximae scientiae Sempronius, quem populus

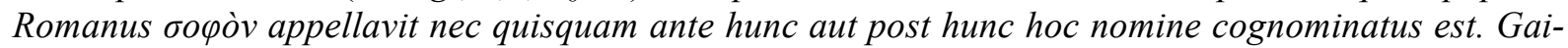
us (sic) Scipio Nasica, qui Optimus a senatu appellatus est, cui etiam publice domus in via sacra data est, quo facilius consuli posset.
} 
Nach diesen (zwei Männer aus dem späten 4. Jahrhundert v. Chr.) war von größter Kennerschaft Sempronius (Plebejer, Konsul 304 v. Chr. und seit 300 pontifex), den das römische Volk ,den Weisen“ nannte; weder vor noch nach ihm hat jemand diesen Beinamen erhalten. Und Scipio Nasica (wohl Publius Scipio Nasica, der Konsul von 162 und 155 v. Chr., 159 Zensor), vom Senat mit dem Titel „der Beste“ ausgezeichnet, erhielt sogar ein Haus an der Heiligen Straße (sie führte durch das Forum) auf Staatskosten, damit er für alle, die Rechtsrat suchten, leichter erreichbar war.

Vertraten Juristen jemanden vor Gericht, was an sich nicht ihre Aufgabe, sondern Sache der Rhetoren war, so konnte das freilich etwas kosten; auch nahmen sie freiwillige Leistungen an, mögen sie auch erst im Testament des Beratenen bedacht worden sein. Rechtsunterricht war oft entgeltlich, wie sonstiger Unterricht, nur konnte ein Rechtslehrer sein Honorar nicht einfordern. Ulpian schrieb 215 n. Chr.: ${ }^{51}$

[71] ... denn die Rechtswissenschaft ist eine höchst ehrwürdige Sache, aber von der Art, dass ihr Wert nicht auf Heller und Pfennig bewertet werden sollte; sie würde entehrt, wenn jemand gerichtlich fordern würde, was ihm bei Eintritt in dieses Heiligtum hätte angeboten werden müssen. Es gibt nämlich Dinge, die anzunehmen durchaus ehrenhaft wäre, die zu fordern jedoch unehrenhaft ist.

Übrigens konnten auch Lehrer der Philosophie ihr Honorar nicht einklagen, was andere Lehrer: der Grammatik, Rhetorik, Landvermessung, Medizin usf. durchaus konnten. ${ }^{52}$

So entwickelte sich seit dem 2. Jahrhundert v. Chr. eine rein weltliche Rechtswissenschaft mit juristischer Fachliteratur, angeregt von der griechischen Fachschriftstellerei. In freier, nunmehr oft literarischer Diskussion durchdrang sie die ganze Rechtsordnung, die sie als Einheit zu verstehen unternahm, die frei von inneren Widersprüchen sein musste. Die einzelnen Rechtsfragen wurden im gemeinsamen Bemühen um die gerechteste Lösung öffentlich diskutiert. Die daraus hervorgegangene Rechtsliteratur wurde bis ins 20. Jahrhundert die schlechthin klassische genannt.

Die vielen Meinungsverschiedenheiten unter den Juristen und ihre oft sehr subtilen Argumente konnten Außenstehende allerdings auch verwirren. Nicht alle fanden sich mit der großen Macht dieser Zunft ab; vielmehr gab es auch Bekundungen völliger Ablehnung der

\footnotetext{
${ }^{51}$ Ulpian: De omnibus tribunalibus VIII (in Dig., 50, 13, $1 \S 5$ ): ... est quidem res sanctissima civilis sapientia, sed quae pretio nummario non sit aestimanda nec dehonestanda, dum in iudicio honor petitur, qui in ingressu sacramenti offerri debuit. Quaedam enim tametsi honeste accipiantur, inhoneste tamen petuntur.

${ }^{52}$ Dazu Ulpian, ebenda pr. $-\S 6$. Zu den Lehrern der Philosophie äußerten sich auch Kaiser Antoninus Pius (herrschte 138 bis $161 \mathrm{n}$. Chr.), wie der jüngere Jurist Modestin, ein Schüler Ulpians, in seiner Schrift De excusationibus II (in Dig., 27,1,6 § 7) berichtet; und der etwas ältere Jurist Papinian: Digesta responsa I (in Dig., 50,5,8 § 4).
} 
Juristen, bei einfachen Leuten ebenso wie bei Intellektuellen. ${ }^{53}$ Das Selbstbewusstsein dieser trotz allem einigermaßen geschlossen auftretenden Gruppe, die grundsätzlich staatstreu eingestellt war und oft unbeugsam urteilte, wirkte auf nicht wenige provozierend. Bei politischen Entscheidungen konnte ihr Festhalten an Rechtspositionen auch großen Schaden anrichten. So führte die strikte Erfassung der in Rom lebenden Italiker ohne römisches Bürgerrecht und ihre Ausweisung durch ein Gesetz, das der hochangesehene Jurist Quintus Mucius Skävola 95 v. Chr. eingebracht hatte, zum Bundesgenossenkrieg 91-89 v. Chr. (dazu sofort). Und im 6. Jahrhundert n. Chr. gab der vom Kaiser hochgeschätzte Jurist Proculus diesem einen Rat, dessen Befolgung auf das persische Herrscherhaus beleidigte $;{ }^{54}$ die beiden Reiche zerfleischten fortan einander.

[72] Insgesamt betrachtet hatten die Juristen in der römischen Gesellschaft von den Anfängen im 5. und 4. Jahrundert v. Chr. bis ins 6. Jahrhundert n. Chr. einen festen Platz. Das bezeugen bis in die Spätantike Nichtjuristen aller Schichten: Cicero, ${ }^{55}$ Horaz, ${ }^{56}$ die Kaiser Augustus und Vespasian, ${ }^{57}$ Juvenal, ${ }^{58}$ Plinius d. J., ${ }^{59}$ Tacitus, ${ }^{60}$ Gellius, ${ }^{61}$ die Kaiser Hadrian, Septimius Severus, Alexander Severus und Diokletian, ${ }^{62}$ Junior, Aurelius Victor, Augustin, Eusebius von Nantes ${ }^{63}$ und die Kaiser Theodosius I., Theodosius II. und Justinian. ${ }^{64}$ Zur einheitlichen Anwendbarkeit des römischen Rechts im ganzen römischen Erdkreis (orbis Romanus) hat nicht wenig dazu beigetragen, dass die Juristen als Berater der Richter, Schriftsteller oder Minister des Kaisers das römische Recht ständig verfeinerten und auf neue Herausforderungen abstimmten. Wie aufgeschlossen diese Zunft Neuerungen gegenüber war, zeigt sich auch daran, dass viele von unten oder von außen dazustießen und alsbald integriert wurden; allein Fachkompetenz zählte. Oft wurden gerade sie die einflussreichsten Vertreter: zur Zeit des Stadtstaates aus dem Umland Coruncanius, später aus der Provinz im 2. Jahrhundert Julian aus

\footnotetext{
${ }^{53}$ Dazu etwa D. Nörr, Rechtskritik in der römischen Antike (München 1974); und D. Liebs, Der ungeliebte Jurist in der römischen Welt, Zeitschrift der Savigny-Stiftung für Rechtsgeschichte Romanistische Abteilung 123 (2006), 1-18; zu Firmicus Maternus ders., Italien (soeben Fn. 49), 81-88.

${ }_{54}^{54}$ D. Liebs, Hofjuristen der römischen Kaiser bis Justinian (München 2010), 130-134.

${ }^{55}$ Cicero, Pro Caecina, 65-70; ders., De oratore, 1,165-207 u. 3,135; ders., Orator, 142-44; u. ders., De officiis, 2,65; dazu J. Christes: Bildung und Gesellschaft (Darmstadt 1975), 142-150.

${ }^{56}$ Horaz, Satiren, 1,1,9f.; u. 2,1.

${ }^{57}$ Liebs, Hofjuristen (soeben Fn. 54), 18-22 u. 26f.

${ }^{58}$ Juvenal, Satiren, 4, 75-81; u. dazu Liebs:, Hofjuristen (oben Fn. 54), 27-30.

${ }^{59}$ Plinius, Epistulae, 1,22; u. 8,14; sowie 7,24,8.

${ }^{60}$ Tacitus, Annalen, $1,76,1 ; 1,79 ; 3,70$ u. $75 ; 4,58 ; 6,26 ; 12,11$ f; $13,30,2 ; 13,41$ u. $48 ; 14,42-45 ; 15,52$; 16,7-9 u. 22.

${ }^{61}$ Gellius, Noctes Atticae, 1,12,1; 7,5,1; 13,10,1-3; u. $20,1$.

${ }^{62}$ Liebs, Hofjuristen (oben Fn. 54), 33-39, 51-59, 68-75 u. 81-87.

${ }^{63} \mathrm{Zu}$ diesen vier (Junior verfasste die Expositio totius mundi und Euseb die Historia Augusta) Liebs, Italien (oben Fn. 49), 88-92 u. 101-119.

${ }^{64} \mathrm{Zu}$ ihnen Liebs, Hofjuristen (oben Fn. 54), 103-106, 112-125 u. 134-152.
} 
Kleinafrika, ebenso Papinian etwas später, im 3. Ulpian aus Syrien, im 4. Hermogenian gleichfalls aus dem Osten, im 5. etwa Dardanus aus Gallien und im 6. Tribonian, der aus Pamphylien im südlichen Kleinasien in die Hauptstadt gekommen war. ${ }^{65}$

\section{AllgemeingÜltige MaßstäBE}

\section{Gleichheit vor dem Gesetz}

Dass alle Menschen rechtlich gleich zu behandeln, vor dem Gesetz gleich sind, war im römischen Gemeinwesen für damalige Verhältnisse bemerkenswert weit entwickelt.

a) Sklaven und Freie

Zwar herrschte wie in allen antiken und auch noch in den frühmittelalterlichen Rechtsordnungen Sklaverei; Sklaven hatten, bevor das Christentum ganz allmählich Verbesserungen herbeiführte, keine Rechte. ${ }^{66}$ Freie ohne römisches Bürgerrecht hatten weniger Rechte als die römischen Bürger wo immer sie lebten; auch das war im Altertum und im Mittelalter nicht anders denkbar. Aber auch unter den römischen Bürgern gab es Abstufungen von Rechts wegen. So hatten Frauen weniger Rechte als Männer und traf niedrig Gestellte (humiliores) eine härtere Behandlung vor allem im Strafverfahren - sie durften gefoltert werden - und bei den Leib- und Lebensstrafen, als Angehörigen der Oberschicht, den honestiores zugemutet wurde.

aa) Die Freilassung der Sklaven war nach römischem Recht leichter und würdiger als anderswo. Man entwickelte einfallsreich Rechtsakte wie die Freilassung mittels Stab oder Steuererklärung (manumissio vindicta und censu). Der Herr ging mit dem Unfreien zum Richter und ein Beliebiger, später kurzerhand ein Gerichtsdiener behauptete verabredungsgemäß, der bzw. die Betreffende sei frei, indem er ihn bzw. sie mit einem Stab berührte. Dazu schwieg der Herr, woraufhin der Richter die Freihei feststellte. Oder der Sklave gab vor dem zuständigen Magistrat im Beisein seines Herrn eine Steuererklärung ab. Sklaven letztwillig durch Testa-

\footnotetext{
${ }^{65} \mathrm{Zu}$ ihnen allen kurz mit weiteren Nachweisen Liebs: Hofjuristen (oben Fn. 54), 36-38, 42f., 45f., $52-$ 54, 56, 62-64, 69f., 85 f., 108-111 u. 136-143; vgl. schon ders.: Römische Provinzialjurisprudenz, in Aufstieg und Niedergang der römischen Welt II 15 (Berlin 1976), 288-362.

${ }^{66}$ Dazu etwa Th. E. J. Wiedemann: Slavery (Oxford $\left.{ }^{2} 1992\right)$; u. U. Roth (Hg.): By the sweat of your brow. Roman slavery in its socio-economic setting (London 2010); u. die Serie Forschungen zur antiken Sklaverei mit 39 Bänden und bisher 14 Bänden Beihefte. Knappe Textsammlung zu allen Aspekten der Sklaverei mit deutscher Übersetzung: W. Eck u. J. Heinrichs: Sklaven und Freigelassene in der Gesellschaft der römischen Kaiserzeit (Darmstadt 1993).
} 
ment freizulassen war seit je gültig. Im 1. Jahrhundert v. Chr. gehörte es sich, wie cicero berichtet, einen Sklaven, der sechs Jahre lang treu gedient hat, freizulassen. Die Freilassungen nahmen sol[74]che Ausmaße an, dass Augustus Beschränkungen einzuführen für nötig hielt.

Rechtsfolge all dieser Freilassungen war, dass der Sklave nicht nur frei, sondern sogleich auch römischer Bürger wurde, einzigartig in der alten Welt. Zwar waren seine Rechte noch beschränkt, vor allem durch Pflichten gegenüber seinem früheren Herrn; seine nach der Freilassung gezeugten Kinder aber waren frei geborene Vollbürger. Bei der Freilassung durch Testament bestanden diese Pflichten gegenüber dem verstorbenen Erblasser, also praktisch nicht; allenfalls könnten sie auf seine Abkömmlinge übergegangen sein, doch hat das vermutlich erst Justinian eingeführt. Und die Juristen entwickelten den Grundsatz, dass, wenn rechtlich zweifelhaft war, ob jemand frei, insbesondere freigelassen worden war, im Zweifel für die Freiheit zu entscheiden sei (favor libertatis, Begünstigung der Freiheit).

Im Lauf der Zeit wurden auch formlose Freilassungen anerkannt wie die Freilassung unter Freunden (manumissio inter amicos), etwa bei einem Gastmahl, die Freilassung durch Zuziehung zur Tafel (manumissio per mensam) und schriftliche Freilassung durch Zustellung eines Freibriefs (manumissio per epistulam). Allerdings verschaffte eine solche Freilassung ohne Beteiligung einer Behörde kein Bürgerrecht. 19 n. Chr. aber erging ein Gesetz, wonach auf diese Weise Freigelassene immerhin das latinische Bürgerrecht erhielten. ${ }^{67}$ Beim Tod eines formlos Freigelassenen ging allerdings das von diesem zusammengebrachte Vermögen, soweit er es nicht zu Lebzeiten veräußert hatte, vollständig an den Freilasser oder dessen Erben über; bei förmlich Freigelassenen nur ein Teil, je nach dem, wie viele eheliche Kinder er hatte.

Freigelassene wurden oft sehr reich; schon die Aussicht auf Freilassung, vor allem aber frei geworden zu sein bedeutete einen großen Ansporn. Handwerk und Gewerbe waren vielfach in der Hand von Freigelassenen, die unverhältnismäßig viel zum römischen Wirtschaftsleben beitrugen. ${ }^{68}$

bb) Die Kaiser haben aber auch die Lage der Sklaven, die im Sklavenstand verblieben, allmählich verbessert. Die erste einschlägige Bestimmung stammt von Claudius. Er bestimmte,

\footnotetext{
${ }^{67}$ Zur lex Iunia Norbana de manumissionibus s. etwa A. J. B. Sirks, The lex Iunia and the effects of informal manumission and iteration, in Revue internationale des droits de l'antiquité 30 (1983), 211 292.

${ }^{68}$ Siehe etwa G. Alföldy: Römische Sozialgeschichte (Wiesbaden ${ }^{4} 2011$ ), 175-179, 183f. u. 193-197; u. P. Zanker, Grabreliefs römischer Freigelassener, in Jahrbuch des Deutschen Archäologischen Instituts 90 (1975), 267-315. F. De Martino: Wirtschaftsgeschichte des alten Rom (München 1985), 95f., 130, 203, 540 u. 550, hebt hervor, dass die Aussicht auf Freilassung die Sklaven zu produktiver Arbeit anspornte.
} 
dass ein Skla[75]venhalter, der einen seiner Sklaven ungerechtfertigt tötete, wegen Totschlags nach den allgemeinen Gesetzen zu bestrafen; sei. ${ }^{69}$ gerechtfertigt war Hinrichtung des eigenen Sklaven nur, wenn eine todeswürdige Schuld im Hausgerichtsverfahren festgestellt wurde; darüber entschied nicht er allein, sondern ein consilium erfahrener Männer. Seit dem 2. Jahrhundert n. Chr. konnte auch übermäßige Züchtigung eines Sklaven zu einem Strafverfahren gegen den Herrn beziehungsweise die Herrin führen, nämlich wenn es dem Sklaven gelang, zu einer Kaiserstatue zu fliehen. Dann musste der zuständige Magistrat den bzw. die Geflohene anhören und Maßnahmen und Strafen verhängen, so den Herrn bzw. die Herrin zu leichter Verbannung verurteilen. Vor allem konnten schlecht behandelte Sklaven ihren Herren weggenommen werden und mit der Maßgabe verkauft werden, dass er frei wird, wenn er wieder in die Gewalt seines gewalttätigen Herrn gelangt. ${ }^{70}$ Auch eine einem fremden Sklaven zugefügte Injurie wie leichte Körperverletzung, Freiheitsberaubung oder Beleidigung, konnte wie die einem Freien zugefügte geahndet werden, d. h. ein deswegen Verurteilter - ein Urteil konnte freilich nur der Herr dieses Sklaven bewirken - musste diesem nicht nur eine Geldbuße zahlen, sondern verlor auch seine bürgerlichen Ehrenrechte. ${ }^{71}$ In bestimmten Fällen konnte ein Sklave gegen seinen Herrn sogar gerichtlich vorgehen, ${ }^{72}$ insbesondere wenn dieser ihm die Freiheit vorenthielt, die ihm von Rechts wegen zustand, etwa indem ein Erbe das Testament mit der Freilassung verschwinden ließ; oder wenn ein Herr mit seinem Sklaven vereinbart hatte, dass dieser sich freikaufen kann, sich jedoch, als es so weit war, nicht mehr daran halten wollte; ${ }^{73}$ schließlich auch, wenn der Herr bestimmte gemeingefährliche Verbrechen beging.

\section{b) Römisches Bürgerrecht}

Wie schon die Rechtsfolgen der Freilassung ergaben, gewährten die Römer das römische Bürgerrecht großzügiger als alle anderen antiken Gemeinwesen. Zwar gab es zwischendurch auch Zeiten der Abschließung, so in den späten 90er Jahren v. Chr., was den Bundesgenossenkrieg zur Folge hatte (91-89 v. Chr.). Zu seiner Bewältigung verlieh Rom nach und nach allen Italikern bis zum Po das römische Bürgerrecht. Cornelius Sulla hat rund 10000 Sklaven

\footnotetext{
${ }^{69}$ Sueton, Claudius, 25,2 .

${ }^{70}$ Dazu R. Gamauf: Ad statuam licet confugere. Untersuchungen zum Asylrecht im römischen Prinzipat (Frankfurt am Main 1999); u. Liebs: Vor den Richtern Roms (oben Fn. 35), 127-139.

${ }_{71}$ So Caracalla am 29. Juli 208 (in Cod. Just., 2,11,10): Iniuriarum ex persona quoque servi damnatus infamia notatur.

${ }_{72}$ Allgemein dazu D. Liebs: Hermogenians iuris epitomae. Zum Stand der römischen Jurisprudenz im Zeitalter Diokletians (Göttingen 1964), 43-46.

${ }^{73}$ Susanne Heinemeyer, Der Freikauf des Sklaven mit eigenem Geld - Redemptio suis nummis (Berlin 2013); dazu D. Liebs, Klio 97 (2015) 288-92.
} 
freigelassen, die er zum großen Teil aus den günstig ersteigerten Vermögen seiner für vogelfrei erklärten politischen Gegner [76] bezogen hatte; dadurch wurde sein Familienname (Cornelius) für lange Zeit der verbreitetste im Reich. Cäsar bürgerte viele Gallier ein, ${ }^{74}$ machte sie sogar zu Senatoren; ${ }^{75}$ auch allen Ärzten und Lehrern in Rom gewährte er das Bürgerrecht. ${ }^{76}$ Augustus hielt sich etwas mehr zurück, ${ }^{77}$ ließ sich jedoch das Recht einräumen, beliebige Personen nach Ermessen einzubürgern; und fortan hatten alle Kaiser dieses Recht und übten es aus, mehr oder minder großzügig. Regelmäßig erhielt es, wer als Nichtbürger in den Hilfstruppen, also vor allem in der Flotte, den Reiterverbänden und anderen Sondereinheiten 25 Jahre lang treu gedient hatte. Bei der feierlichen Entlassung wurde es ihm zusammen mit dem Recht verliehen, eine Frau seiner Wahl, also insbesondere auch eine Nichtrömerin zu heiraten und mit ihr römische Bürger zu zeugen. Außerdem erhielten die Veteranen Land in eigens für sie angelegten Kolonien und angesparten Sold als Kapital, wodurch sie sogleich zur landstädtischen Oberschicht gehörten. Seit dem mittleren 2. Jahrhundert n. Chr. siedelten sie nicht mehr in eigens für sie angelegten Kolonien. ${ }^{78}$ Überdies gewährte etwa Kaiser Claudius (er herrschte 41 bis 54 n. Chr.) dem gallischen Adel das volle Bürgerrecht; ${ }^{79}$ Nero (54 bis 68) Sportlern und ihm gewogenen Kampfrichtern; Vespasian (69 bis 79) gab ganz Hispanien das latinische Recht, eine Vorstufe des römischen Bürgerrechts; Hadrian (117 bis 138) bedachte viele Intellektuelle und Künstler damit. ${ }^{80}$ Die Neubürger nahmen Vor- und Familiennamen (praenomen und nomen) dessen an, der ihnen das Bürgerrecht verschafft hatte, dem sie ihren bisherigen Namen als römischen Beinamen (cognomen) hinzufügten; so wurden die Vor- und Familiennamen der Kaiser die verbreitetsten. Caracalla (211 bis 217, seit 197 offiziell Marcus Aurelius Antoninus) gab das römische Bürgerrecht nahezu allen freien Reichsbewohnern, die [77] es noch nicht hatten (constitutio Antoniniana, ${ }^{81} 212$ n. Chr.), mehr als die Hälfte der freien Bevölkerung. So hießen fortan die meisten mit Vor- und Familiennamen Marcus Aurelius.

\footnotetext{
${ }^{74}$ Sueton, Iulius, 24,2 .

${ }^{75}$ Sueton, Iulius, 80,2 .

${ }^{76}$ Sueton, Iulius, 42,1 .

${ }^{77}$ Sueton, Augustus, 40,3. Andererseits konnte er ganzen Stadtgemeinden wie dem treuen Sagunt in Spanien und auch sonst großzügig das Bürgerrecht verleihen.

${ }^{78}$ Siehe zu diesem Komplex W. Eck u. H. Wolff (Hgg.): Heer und Integrationspolitik. Die römischen Militärdiplome als historische Quelle (Köln 1986).

${ }^{79}$ Corpus inscriptionum Latinarum XIII, Nr. 1668; u. Tacitus, Annalen, 11,24.

${ }^{80} \mathrm{Zu}$ Nero s. Sueton, Nero, 12,1; u. 24,2; zu Vespasian und den Folgen J. Andreu Pintado: Edictum, Municipium y Lex. Hispania en época Flavia (Oxford 2004); zu Hadrian D. Liebs: Älius Marcian. Ein Mittler des römischen Rechts in die hellenistische Welt, Zeitschrift der Savigny-Stiftung für Rechtsgeschichte Romanistische Abteilung 128 (2011), 39-82, hier 40f.

${ }^{81}$ Bruchstückhaft erhalten: Gießener Papyrus Nr. 40 I; s. dazu etwa K. Buraselis: $\Theta \varepsilon i ́ \alpha \delta \omega \rho \varepsilon \dot{\alpha}-D a s$ göttlich-kaiserliche Geschenk. Studien zur Politik der Severer und zur constitutio Antoniniana (Wien 2007); u. dazu D. Liebs, in Zeitschrift der Savigny-Stiftung für Rechtsgeschichte Romanistische Abteilung 126 (2009), 509-514.
} 
Der bei den Römern ohnehin einfallslose Vorname wurde mit der Zeit ganz weggelassen, der Familienname abgekürzt oder ganz weggelassen und dem Beinamen agnomina, supernomina und signa angefügt.

Seitdem lebten alle Reichsbewohner nach römischem Recht; nur Staatenlose (dediticii), und das waren nicht viele, waren von seinen Vorteilen ausgeschlossen. Allerdings nahm man Rücksicht auf angestammtes Recht, die sogenannten Volksrechte der durch die Verleihung des Bürgerrechts an alle eher formell, allenfalls oberflächlich romanisierten Neubürger. Ihre mit römischen Grundsätzen vereinbaren Eigenheiten ließ man als lokales Gewohnheitsrecht fortgelten. ${ }^{82}$ Manche Einrichtungen der Volksrechte übernahm man sogar in das eigene Recht. So haben die römischen Juristen Teile des griechischen Seerechts, insbesondere aus dem der Stadtrepublik Rhodos, hervorgegangen aus jahrhundertelangen Erfahrungen mit Seehandel, in das römische Recht übernommen und weiter verfeinert. ${ }^{83}$ Den aktiven Soldaten, die mehr als andere mit ihrem vorzeitigen Tod rechnen mussten, wurde erlaubt, Testamente nach Belieben $\mathrm{zu}$ errichten, was bei den vielen Nichtrömern im Heer praktisch bedeutete: nach heimischen Gewohnheiten. Zunächst hatten [78] Cäsar, Titus und Domitian das ihren Soldaten vorübergehend eingeräumt, bis Trajan um $100 \mathrm{n}$. Chr. eine allgemeine Regelung traf. ${ }^{84}$

\section{c) Männer und Frauen}

Die römischen Frauen waren, anders als sonst im Altertum, den Männern insofern gleichgestellt oder wurden es in der Kaiserzeit, als im Erbfall Frauen, die mit dem Erblasser agnatisch, d. h. in männlicher Linie verwandt waren, seit je einen ebenso großen Erbteil wie die Männer erhielten. So erbten, solange der Erblasser nicht durch Testament etwas anderes bestimmt hatte, Töchter vom Vater ebenso viel wie Söhne, mangels Kindern die Schwestern mit gleichem Vater, auch wenn die Mutter verschieden war, ebenso viel wie die Brüder und die über den Vater verwandten Tanten ebenso viel wie die entsprechenden Onkel. Augustus hatte so-

\footnotetext{
${ }^{82}$ Dazu etwa D. Liebs, Zur Geschichte der Volksrechte im römischen Reich, in Studi in onore di Remo Martini II (Mailand 2009), 449-72. Allgemein zur Romanisierung der Mittelmeerwelt G. Alföldy, in Zsolt Visy (Hg.): Limes XIX. Proceedings of the XIX $X^{\text {th }}$ International congress of Roman Frontier Studies Pécs, Hungary, September 2003 (Pécs 2005), 25-56.

${ }^{83}$ Siehe besonders Volusius Mäcians wohl wirklich in griechischer Sprache verfasste Monografie $E x$ lege Rhodia, wenn wir daraus auch nur mehr ein kurzes Bruchstück haben: in Dig., 14,2,9; ferner die einschlägigen Titel in den Quaestiones des im hellenistischen Osten wirkenden römischen Provinzialjuristen Callistratus, woraus ein größeres Fragment auf uns gekommen ist: in Dig., 14,2,4; und denjenigen in den Sententiae von Pseudo-Paulus: 2,7. Dazu K. M. T. Atkinson, Rome and the Rhodian sea-law, IVRA. Rivista internazionale di diritto romano ed antico 25 (1974), 46-98; D. G. Letsos: Nomos Rhodioon nautikos. Untersuchungen zu Seerecht und Handelsschiffahrt in Byzanz: Das Seerecht der Rhodier (Rhodos 1996); u. A. Földi, Einige Probleme der lex Rhodia im römischen Recht, in P. Mach u. a. (Hgg.): Ius Romanum schola sapientiae. Pocta Petrovi Blahovi k 70. narodeninám (Trnava 2009), 111-130.

${ }^{84}$ Siehe Inst., 2,11; Dig., 29,1; u. Cod. Just., 6,21.
} 
dann eingeführt, dass die grundsätzliche Beaufsichtigung römischer Frauen, die keinen Vater mehr hatten, durch einen lebenslänglichen Geschlechtsvormund entfällt, wenn sie dreimal geboren hatten. Im christlichen 4. Jahrhundert, als Enthaltsamkeit höher bewertet wurde, erhielten alle Frauen das Dreikinderrecht. Hadrian bestimmte, wenn Kinder vor ihrer Mutter starben und diese das Dreikinderrecht hatte, sie - sofern das Kind kein gültiges Testament errichtet hatte - wenigstens entferntere Agnaten von einer etwa vorhandenen Erbschaft ausschloss, Geschwister vom vorverstorbenen Vater also nicht; solange dieser lebte, gehörte alles ihm, hatte das Kind kein eigenes Vermögen. Mark Aurel bestimmte schließlich, dass auch umgekehrt beim Tod der Mutter ihre Kinder ihren Seitenverwandten vorgehen.

Von öffentlichen Ämtern waren Frauen ausgeschlossen; das galt auch für private Ämter wie die Stellung als Familienoberhaupt (pater familias), das Amt eines Vormunds über unmündige Kinder, die keinen Vater mehr hatten, und wurde auch auf die Vertretung anderer vor Gericht erstreckt. Dagegen kannten etliche Volksrechte, darunter das hellenistischägyptische und das jüdische Recht die Möglichkeit, beim Tod des Vaters die Witwe zum Vormund über die gemeinsamen minderjährigen Kinder zu bestellen und mit der Verwaltung des ihnen vom Vater hinterlassenen Vermögens zu betrauen. Die römischen Behörden akzeptierten das. Auch als seit 212 alle nach römischem Recht lebten, fanden die römischen Autoritäten einen Weg, die bisherigen Gepflogenheiten in der Sache beizubehalten. Zwar musste ein Mann den [79] Vormund spielen, doch übertrug er die tatsächliche Verwaltung des Kindesvermögens der Witwe. 390 n. Chr. räumte Theodosius dieser dann offen die Möglichkeit ein, selbst Vormund ihrer Kinder zu sein. ${ }^{85}$ Zu keinem Kompromiss mit volksrechtlichen Traditionen war Rom dagegen bereit, wenn es um die Gleichberechtigung der Töchter im Erbfall ging. Das armenische Erbrecht benachteiligte sie mannigfach, wogegen Kaiser Justinian 535 und $536 \mathrm{n}$. Chr. einschritt. ${ }^{86}$

Seit alter Zeit, wie man aus der Sage vom Raub der Sabinerinnen ablesen kann, bis in die Spätantike war es römische Politik, Zugezogene und allmählich auch die unter römische Herrschaft Geratenen - soweit sie sich für das Reich gewinnen ließen - zu integrieren, ${ }^{87}$ wobei Rücksicht auf Eigenheiten genommen und den lokalen Gemeinschaften, insbesondere den - früher meist selbständigen - Städten nach Möglichkeit Autonomie eingeräumt wurde.

\footnotetext{
${ }^{85}$ In Cod. Theod., 3,17,4; dazu T. Chiusi, Zur Vormundschaft der Mutter, Zeitschrift der SavignyStiftung für Rechtsgeschichte Romanistische Abteilung 111 (1994), 155-196.

${ }^{86}$ Ed. Iust., 3 (23. Juli 535); u. Nov. Iust., 21 (18. März 536).

${ }^{87}$ Dazu jüngst etwa R. Wiegels, Imperiale Herrschaft und provinziales Leben - Integration und Provinzialismus im römischen Reich des 2. Jahrhunderts n. Chr., in A. Bauer u. K. H. L. Welker (Hgg.): Europa und seine Regionen. 2000 Jahre Rechtsgeschichte (Köln 2007), 13-47.
} 
2. Ius gentium, ius naturale

Als Rom im 3. Jahrhundert v. Chr. Weltmacht geworden war, war die römische Obrigkeit, beraten von den Juristen, darauf bedacht, dem geltenden römischen Recht eine breitere Grundlage zu geben. In Rom und außerhalb der Hauptstadt lebten viele Fremde, welche die römischen Gerichte anriefen, um ihre Rechte durchzusetzen; meist war deren Heimatrecht, nach dem ihre Konflikte genau genommen zu beurteilen gewesen wären, ${ }^{88}$ nicht, zumindest nicht verlässlich zu ermitteln. 242 v. Chr. richtete man in Rom eine besondere Gerichtsbarkeit für Rechtsstreitigkeiten unter und mit Fremden ein, womit ein besonderer praetor eingerichtet wurde, der praetor peregrinus. Seine Rechtsprechung wurde ein Motor des [80] Fortschritts. Unter dem Einfluss der griechischen Philosophie entwickelten die Juristen den Gedanken, dass es Rechtseinrichtungen gibt, die allen Kulturvölkern gemeinsam seien, was sie dementsprechend ius gentium (Recht der Völker) nannten; damit war gemeint, dass sie bei den verschiedenen Völkern oder vielmehr Rechtsgemeinschaften, die römische eingeschlossen, ganz entsprechend gehandhabt würden. Das waren vor allem Regeln des Warenkaufs und sonstiger Verkehrsgeschäfte, aber auch die Sklaverei aufgrund von Kriegsgefangenschaft oder Geburt von einer Sklavin. ${ }^{89}$ Auf Lehren insbesondere des Aristoteles aufbauend sprechen die Juristen in einem weiteren Sinn auch von ius naturale, womit sie ein allen Menschen gemeinsames Idealrecht meinen, das im Gegensatz zum geltenden Recht keine Sklaverei kennt, vielmehr alle Menschen für von Natur aus frei erklärt und wozu auch die Rechtssätze zur Aneignung durch Besitzergreifung, der Übereignung durch Übergabe oder der Blutsverwandtschaft durch eheliche Geburt gehören. Ulpian ging noch weiter und zog in seinem Anfängerlehrbuch auch rechtliches Verhalten der Tiere in Betracht: ${ }^{90}$

\footnotetext{
${ }^{88}$ So zu zwei sehr speziellen Rechtsfragen Kaiser Trajan bei Plinius: Epistulae, 10,109; u. Gajus: Institutionen, 3,120. Allgemein zu diesem Problem H. Lewald, Conflits de lois dans le monde grec et romain, Labeo 5 (1959), 334-369 (zuerst 1946); H. J. Wolff, Das Problem der Konkurrenz von Rechtsordnungen in der Antike (Heidelberg 1979); H. M. Cotton: Private international law or conflict of laws: Reflections on Roman provincial jurisdiction, in Haensch/Heinrichts (oben Fn. 23), 234-255; u. C. Cascione, Zur Anwendung von fremdem Privatrecht durch den römischen Prätor", in M. Avenarius u. a. (Hgg.): Ars iuris. Festschrift für Okko Behrends zum 70. Geburtstag (Göttingen 2009), 6170 .

${ }^{89}$ Dazu vor allem M. Kaser: Ius gentium (Köln 1993), u. dazu K.-H. Ziegler, Zeitschrift der SavignyStiftung für Rechtsgeschichte Romanistische Abteilung 112 (1995), 571-580; u. O. Behrends, Che cos'era il ius gentium antico?, in L. Labruna (Hg.): Tradizione romanistica e Costituzione I (Neapel 2006), 481-514.

${ }^{90}$ Ulpian: Institutiones I (in Dig., 1,1,1 § 3): Ius naturale est, quod natura omnia animalia docuit; nam ius istud non humani generis proprium, sed omnium animalium, quae in terra, quae in mari nascuntur, avium quoque commune est. Hinc descendit maris atque feminae coniunctio, quam nos matrimonium appellamus, hinc liberorum procreatio, hinc educatio; videmus etenim cetera quoque animalia, feras etiam istius iuris peritia censeri.
} 
Naturrecht ist, was die Natur alle Geschöpfe gelehrt hat; denn dieses Recht ist nicht nur dem Menschengeschlecht eigen, sondern Gemeingut aller Geschöpfe, die auf der Erde und im Wasser geboren werden, und auch der Vögel. Daher leitet sich die Verbindung von Mann und Frau ab, was bei uns (d. h. den Menschen) Ehe ist, daher die Hervorbringung von Nachwuchs und seine Aufzucht; denn wir sehen, dass auch die anderen Geschöpfe, sogar die wilden Tiere sich von der Erfahrung dieses Rechts leiten lassen.

Dass Ulpian daraus praktische Folgerungen in dem Sinn gezogen hätte, dass Rechte von Tieren auch eingeklagt werden könnten, etwa durch einen Sachwalter, ist allerdings nicht ersichtlich. ${ }^{91}$ Aber in ande[81]ren Bereichen haben die römischen Juristen aus dem ius naturale durchaus auch konkrete Verbesserungen der geltenden Rechtslage abgeleitet. ${ }^{92}$

\section{Fides, bona fides und aequitas}

Zur Beurteilung der Frage, welche konkreten Verhaltensweisen in einem Vertragsverhältnis gerecht wären, juristisch gesprochen: welche genauen Rechte und Pflichten die beteiligten Vertragspartner haben, wurde Leitfaden der entwickelten römischen Rechtsordnung ein übergreifender, potentiell die Interessen aller berücksichtigender, gleichwohl fest in der römischen Sozialmoral verankerter Maßstab: die fides (bona), zu übersetzen am besten mit, Verlässlichkeit ${ }^{9}{ }^{93}$ Wenn ein traditionsbewusster Römer etwas auf seine fides genommen hatte, konnte man sicher sein, dass er es einhalten würde. Das galt bei Schutzzusagen, etwa bei Begründung eines Patronats gegenüber einem Klienten oder nach einem militärischen Sieg Roms gegenüber einer sich in die fides des Siegers ergebenden Stadt; ${ }^{94}$ und ebenso bei schlichten Leistungszusagen unter Partnern eines Vertrags, zwischen Bürgern ebenso wie mit Nichtbürgern. Die bona fides wurde durch die Detailarbeit von Juristen mit Autorität zum rechtlichen Kriterium für die Bestimmung sämtlicher Pflichten aus Verträgen der Wirtschaftenden: Kauf-, Dienst-, Werk-, Miet-, Pacht-, Gesellschaftsverträgen und vielen anderen,. Zu nennen ist dazu

\footnotetext{
${ }^{91}$ Kaser, aaO. 70-74.

${ }^{92}$ Kaser, aaO. 54-70; u. W. Waldstein, Natura debere, ius gentium und natura aequum im klassischen römischen Recht, in Annali del Seminario Giuridico della Università di Palermo 52 (2007/8), 431460; ders., Zur juristischen Relevanz der Gerechtigkeit bei Aristoteles, Cicero und Ulpian, in Der Gerechtigkeitsanspruch des Rechts. Festschrift für Theo Mayer-Maly zum 65. Geburtstag (Wien 1996), 1-71; u. ders., Naturrecht bei den klassischen römischen Juristen, in Das Naturrechtsdenken heute und morgen. Gedächtnisschrift für R. Marcic (Berlin 1983), 239-253.

${ }^{93}$ Dazu gründlich L. Lombardi: Dalla fides alla bona fides (Mailand 1961), und hierzu F. Wieacker, Zeitschrift der Savigny-Stiftung für Rechtsgeschichte Romanistische Abteilung 79 (1962), 407-421.

${ }^{94}$ Dazu besonders D. Nörr: Die Fides im römischen Völkerrecht (Heidelberg 1991).
} 
insbesondere Quintus Mucius Skävola, ${ }^{95}$ um 100 v. Chr. pontifex und schließlich pontifex maximus, auch Politiker: 95 v. Chr. Konsul und 94/93 Statthalter der reichen Provinz Asia, das westliche Kleinasien. Gegenbegriff der bona fides war dolus malus (Arglist); und Skävola hatte als oberster Richter der Provinz eingeführt, dass niemand Arglist hinzunehmenen braucht. Er setzte das auch gegen [82] römische Kapitalisten durch, die griechischen Städten gern Kredite zu Wucherzinsen und mit Verpfändung ihrer Schätze aufdrängten, nur um diese dann, in ein rechtliches Mäntelchen gekleidet, mit nach Hause nehmen zu können; oder sie missbrauchten die ihnen im Rahmen einer Steuerpacht übertragene Befugnis, die Steuern einzuziehen, und pressten mehr heraus, als nach den geltenden Steuergesetzen zulässig war. Die Provinzialen verehrten Skävola deshalb, in jenen Kreisen der römischen Bürgerschaft dagegen war er verhasst; der Senat indessen empfahl allen Statthaltern, seine Provinzverwaltung zum Vorbild zu nehmen. ${ }^{96}$

Im Vertragsrecht wurde aufgrund des Maßstabs der bona fides die Rechtsverbindlichkeit auch formlos abgeschlossener Verkehrsgeschäfte wie Kauf, Werk- und Dienstvertrag, Miete, Pacht usf. herausgearbeitet. Im Lauf des 1. und 2. Jahrhunderts n. Chr. wurden zudem mannigfache Nebenpflichten daraus abgeleitet, ebenso die Rechtsfolgen unvorhergesehener Vertragsstörungen wie Mängel des Vertragsgegenstandes, zufälliger Untergang desselben, Verzögerung der Lieferung und vieles mehr. ${ }^{97}$ In anderen Schuldverhältnissen wie dem zwischen Ehegatten bezüglich der Mitgift galt der Maßstab des aequius melius, des Gerechteren und Besseren. Gewiss waren die römischen Juristen bei Ausfüllung dieser schriftlich formulierten Maßstäbe insofern befangen, als sie von römischen Verhältnissen ausgingen; aber den größten Einfluss gewannen wohl nicht zufällig diejenigen, die sich von der Periferie her, wo sie auch andere Traditionen wahrnahmen, in die römische Tradition hineinbegeben hatten: Paulus, Ulpian und Marcian. ${ }^{98}$ Der Maßstab von Treu und Glauben ist noch heute, nicht nur im deutschen Recht, der wichtigste Motor der Rechtsentwicklung, nicht nur im Privatrecht. ${ }^{99}$

\footnotetext{
${ }^{95}$ Cicero, De officiis, 3,70, u. dazu etwa O. Behrends, Die Wissenschaftslehre im Zivilrecht des Q. Mucius Scaevola pontifex", in Nachrichten der Akademie der Wissenschaften in Göttingen I. Philologisch-historische Klasse (1976), 263-304; u. Kaser, aaO. 14-20.

${ }^{96}$ Kurz zu Person und Gesamtwerk Skävolas D. Liebs, in: W. Suerbaum (Hg.), Handbuch der lateinischen Literatur der Antike I: Von den Anfängen bis Sullas Tod (München 2002), 569-571 = § 195.1.

${ }^{97}$ Überblick über die aus der bona fides abgeleiteten Rechte und Pflichten der Parteien eines Kaufvertrags bei D. Liebs: Römisches Recht - Ein Studienbuch (Göttingen $\left.{ }^{6} 2004\right), 264-299$.

${ }^{98}$ Vgl. Liebs, Älius Marcian (oben Fn. 80), 57-69.

${ }^{99}$ Dazu etwa G. H. Roth: Kommentar zu § 242 BGB, in Münchener Kommentar zum Bürgerlichen Gesetzbuch II (München $\left.{ }^{5} 2007\right), 114-228 ;$ s. a. Jan Busche: Kommentar zu $§ 157$ BGB, ebenda I (52006), 1896-1914.
} 